\title{
DECISIONS
}

\section{Preventing fractures in postmenopausal women: how to assess risk}

\author{
Vincent Fung MD MSc(Pharm), David Kendler MD
}

A 68-year-old postmenopausal woman presents in her family physician's office to discuss the results of her recent bone mineral density test. She has a T-score of -2.2 at the femoral neck and 1.9 at the lumbar spine. She has no history of fracture and is otherwise healthy. She wonders if her low bone density requires treatment.

\section{What is the 10-year risk of fracture?}

There are two models available in Canada to assess risk of fracture: the Fracture Risk Assessment Tool (FRAX; available at www.shef.ac.uk /FRAX) and the Canadian Association of Radiologists and Osteoporosis Canada tool (available at www.osteoporosis.ca). ${ }^{1}$ Recent guidelines issued by Osteoporosis Canada state that the choice of tool is a matter of personal preference and convenience. ${ }^{1}$

The World Health Organization (WHO) launched the FRAX tool in 2008 (Table 1). ${ }^{2}$ It calculates 10-year probabilities of fracture using multiple global observational databases that integrate clinical risk factors and bone mineral density at the femoral neck. Both the risk of hip fracture and the risk of major osteoporotic fracture are calculated. A FRAX tool calibrated to Canadian rates of hip fracture has been available since July 2010.

Table 1: Risk factors assessed by the FRAX tool for assessing risk of fracture

\begin{tabular}{|c|c|}
\hline Risk factor & Possible responses used in model \\
\hline Age, yr & 40-90 \\
\hline Sex & Male or female \\
\hline Weight, kg & Based on individual patient's parameters \\
\hline Height, $\mathrm{cm}$ & Based on individual patient's parameters \\
\hline Previous fracture & $\begin{array}{l}\text { Yes or no; denotes a previous fracture, incurred as an adult, either } \\
\text { spontaneously or as a result of trauma that would not have resulted in a } \\
\text { fracture in a healthy person }\end{array}$ \\
\hline Parent who fractured hip & Yes or no \\
\hline Current smoking & Yes or no \\
\hline $\begin{array}{l}\text { Exposure to glucocorticoid } \\
\text { medications }\end{array}$ & $\begin{array}{l}\text { Yes or no; current or previous exposure to oral glucocorticoid for }>3 \text { mo } \\
\text { (e.g., } \geq 5 \mathrm{mg} / \mathrm{d} \text { prednisolone or equivalent doses of other } \\
\text { glucocorticoids) }\end{array}$ \\
\hline Rheumatoid arthritis & Yes or no \\
\hline Secondary osteoporosis & $\begin{array}{l}\text { Yes or no; as a result of conditions strongly associated with osteoporosis, } \\
\text { such as type I diabetes, osteogenesis imperfecta (in adults), untreated } \\
\text { long-standing hyperthyroidism, hypogonadism or premature menopause } \\
\text { (< } 45 \mathrm{yr} \text { ), chronic malnutrition or malabsorption, and chronic liver disease }\end{array}$ \\
\hline $\begin{array}{l}\text { Alcohol consumption } \geq \\
3 \text { units/d }\end{array}$ & $\begin{array}{l}\text { Yes or no; a unit of alcohol varies between countries (8-10 g of alcohol), } \\
\text { and is equivalent to } 285 \mathrm{~mL} \text { beer, } 30 \mathrm{~mL} \text { spirits, } 120 \mathrm{~mL} \text { wine or } 60 \mathrm{~mL} \\
\text { aperitif }\end{array}$ \\
\hline $\begin{array}{l}\text { Bone mineral density at the } \\
\text { femoral neck, } \mathrm{g} / \mathrm{cm}^{2}\end{array}$ & $\begin{array}{l}\text { Clinician must select the make of the duel-energy X-ray absorptiometry } \\
\text { equipment used before entering the measurement; the field is left blank } \\
\text { for patients who have not had a bone mineral density test }\end{array}$ \\
\hline
\end{tabular}

Used with permission of the WHO Collaborating Centre for Metabolic Bone Diseases, University of Sheffield, Sheffield, UK. FRAX® is registered to Professor J.A. Kanis, University of Sheffield.

Competing interests:

David Kendler is a consultant for Amgen, Novartis, Lilly, Pfizer and Merck; he has received grants from Amgen, Novartis, Lilly, Biosante, GlaxoSmithKline and

Roche; he has received payment for lectures from Amgen, Lilly, Novartis,

Warner Chilcott and Pfizer; and he has been reimbursed for travel expenses by Amgen, Lilly, Novartis, the International Society for Clinical Densitometry and Osteoporosis Canada. No other competing interests were declared.

This article has been peer reviewed.

Correspondence to: Dr. Vincent Fung, vincent.fung@vch.ca

CMAJ 2011. DOI:10.1503 /cmaj.101054 
Upon questioning, our patient confirmed having a 20 pack-year history of smoking with no intention of quitting and that she drinks less than two units of alcohol per day. There is no family history of osteoporosis or fractures. The patient's menopause occurred at 50 years of age, for which she did not receive hormone therapy. The patient has never taken glucocorticoids and has no other medical conditions, but she reports a 3 -inch loss of height over her lifetime. The patient takes $1200 \mathrm{mg}$ of elemental calcium from diet and supplements, as well as $400 \mathrm{IU}$ vitamin D daily. She walks for 30 minutes each day. On examination, the patient weighs $70 \mathrm{~kg}$, with a height of $165 \mathrm{~cm}$ and a body mass index of $25.7 \mathrm{~kg} / \mathrm{m}^{2}$. A spinal examination shows that the patient has an upright posture with no kyphotic deformity. The patient's blood pressure is $135 / 80$. The rest of the examination is unremarkable.

Using the patient's bone mineral density at the femoral neck, the FRAX tool calculates her 10 -year probability of major osteoporotic fracture as $12 \%$, with a $3.8 \%$ 10-year probability of hip fracture. Using the Canadian Association of Radiologists and Osteoporosis Canada tool, the patient would be considered at moderate risk for fracture $(10 \%-20 \%)$.

\section{Is the risk of fracture high enough to warrant medication?}

The WHO defines osteoporosis in a postmenopausal woman as a T-score less than or equal to -2.5 at the total hip, femoral neck or lumbar spine. ${ }^{3}$ The presence of a fragility fracture constitutes a clinical diagnosis of osteoporosis without the need for measuring bone mineral density. By densitometry alone, our patient would have a diagnosis of low bone density (or osteopenia), not osteoporosis.

Guidelines for therapy based on the assessment of 10-year absolute risk of fracture are available for many jurisdictions. The North American Menopause Society and the US National Osteoporosis Foundation recommend that medications be considered for the treatment of osteoporosis in postmenopausal women if any of the following criteria are present: ${ }^{4.5}$ a fracture of the hip or vertebrae (clinical or morphometric); a T-score of less than -2.5 at the lumbar spine, femoral neck or total hip regions; or a Tscore between -1.0 and -2.5 (low bone density) and a 10 -year probability of major osteoporotic

The number needed to treat estimates how many patients in a given risk group will need treatment for a given length of time to prevent one adverse outcome. It is calculated as the inverse of the difference between the proportionate outcomes in the control and treatment groups: $1 /[$ (proportion of outcomes in the control group) - (proportion of outcomes in the treatment group)]. fracture (spine, hip, proximal humerus and wrist) of at least $20 \%$ or a probability of hip fracture of at least 3\%, as calculated using the FRAX tool.

Our patient's 10-year risk of hip fracture using the FRAX calculator is $3.8 \%$, so she exceeds the baseline threshold for pharmacologic treatment as recommended by the North American Menopause Society and the National Osteoporosis Foundation. The patient's risk of hip fracture increased from $2.2 \%$ to $3.8 \%$ because of her history of smoking, although this history did not substantially affect her risk of major fracture.

Osteoporosis Canada guidelines do not specify therapy thresholds for 10-year risk of hip fracture and do not include smoking, family history of fracture or consumption of alcohol as risk factors in their evaluation. For patients at moderate risk, as determined using the Canadian Association of Radiologists and Osteoporosis Canada tool, Osteoporosis Canada's guidelines encourage the consideration of other risk factors in deciding whether medications should be advised. A radiographic image of the patient's spine showed a $25 \%$ wedge compression of the anterior portion of the T12 vertebrae, making her a candidate for pharmacotherapy according to the guidelines of both the North American Menopause Society and Osteoporosis Canada.

Our patient opted to take alendronate. In the Fraction Intervention Trial 2 (FIT-2) of alendronate versus placebo for women with low bone density but no vertebral fracture, alendronate reduced the risk of radiographic vertebral fractures by $44 \%$ overall (relative risk, 0.56 ; $95 \%$ confidence interval, 0.39-0.80; treatment-control difference, $1.7 \%$; number needed to treat, 60$){ }^{6}$

In the Fracture Intervention Trial (FIT), alendronate was shown to have an absolute risk reduction of $7 \%$ (number needed to treat, 14 over $3 \mathrm{yr}$ ) and $1.1 \%$ (number needed to treat, 91 over 3 yr) for hip fracture in people who had previously had a vertebral fracture. ${ }^{7}$

\section{What is the recommended daily intake of calcium and vitamin $D$ for this patient?}

All postmenopausal women, regardless of their bone density, should be encouraged to get an adequate amount of calcium and vitamin $\mathrm{D}$ from their diet and supplements. In women aged 50 years or more, Osteoporosis Canada, the North American Menopause Society and the National Osteoporosis Foundation all recommend a total daily intake of $1200 \mathrm{mg}$ of elemental calcium. ${ }^{1,4,5} \mathrm{~A}$ recent meta-analysis suggests a potential increase in the risk of myocardial infarction with high-dose supplementation of calcium. $^{8}$ 
A recent Osteoporosis Canada guideline on vitamin $\mathrm{D}$ recommends a daily intake of up to 800-2000 IU for women at high risk for osteoporosis or fracture and for older women. ${ }^{1,8}$ The North American Menopause Society and National Osteoporosis Foundation have suggested that 2000 IU per day is the upper limit of safe intake for vitamin D. ${ }^{1,4,5}$ Our patient should also be encouraged to quit smoking and to increase her level of physical activity, specifically the amount of weight-bearing exercise she does, such as walking.

\section{What other evaluation is required and what follow-up is advised?}

Osteoporosis Canada, among other groups, suggests that patients with low bone density be evaluated for secondary causes of bone loss including renal failure, parathyroid disease, thyroid disease, myeloma and, sometimes, vitamin D deficiency. ${ }^{1}$ Laboratory investigations before starting treatment may include complete blood count and tests for levels of creatinine, calcium (corrected for albumin), thyroid-stimulating hormone, alkaline phosphatase and 25-hydroxyvitamin $\mathrm{D}$, as well as serum protein electrophoresis and other tests that are clinically indicated.

A follow-up test of a patient's bone density in one to three years is recommended by Osteoporosis Canada to check for stabilization or increases in bone mineral density. ${ }^{1}$ Declining bone mineral density (beyond the precision error of the measuring facility) suggests inefficacy of treatment in reducing the risk of fracture. Vitamin D should be measured after three to four months of adequate supplementation in patients with low bone density or osteoporosis and should not be repeated if an optimal level (at least $75 \mathrm{nmol} / \mathrm{L}$ ) is achieved. ${ }^{1,9}$

\section{References}

1. Papaioannou A, Morin S, Cheung AM, et al. Guidelines Committee of the Scientific Advisory Council of Osteoporosis Canada. 2010 clinical practice guidelines for the diagnosis and management of osteoporosis in Canada: summary. CMAJ 2010; 182:1864-73.

2. Kanis JA, Johnell O, Oden A, et al. FRAX and the assessment of fracture probability in men and women from the UK. Osteoporos Int 2008;19:385-97.

3. Kanis JA. Assessment of fracture risk and its application to screening for postmenopausal osteoporosis: synopsis of a WHO report. WHO Study Group. Osteoporos Int 1994;4:368-81.

4. Management of osteoporosis in postmenopausal women: 2010 position statement of the North
American Menopause Society. Menopause. 2010; $17: 25-54$.

5. National Osteoporosis Foundation. Clinician's Guide to Prevention and Treatment of Osteoporosis. Washington, DC: National Osteoporosis Foundation 2008.

6. Cummings SR, Black DM, Thompson DE, et al. Effect of alendronate on risk of fracture in women with low bone density but without vertebral fractures: results from the Fracture Intervention Trial. JAMA 1998;280:2077-82.

7. Black DM, Cummings SR, Karpf DB, et al. Randomised trial of effect of alendronate on risk of fracture in women with existing vertebral fractures. Fracture Intervention Trial Working Group. Lancet 1996;348:1535-41.

8. Bolland MJ, Abenell A, Baron JA, et al. Effect of calcium supplements on risk of myocardial infarction and cardiovascular events: meta-analysis. $B M J$ 2010;341:c3691.

9. Hanley DA, Cranney A, Jones G, et al. Guidelines Committee of the Scientific Advisory Council of Osteoporosis Canada. Vitamin D in adult health and disease: a review and guideline statement from Osteoporosis Canada (summary). CMAJ 2010;182: 1315-9.

Affiliations: From the Division of Medical Biochemistry and the Departments of Pathology and Laboratory Medicine (Fung) and the Division of Endocrinology and Department of Medicine (Kendler), Faculty of Medicine, University of British Columbia, Vancouver, BC.

Contributors: Both authors contributed to drafting, revising, and critically reviewing the manuscript and gave their final approval of the version submitted for publication.

Decisions is a series that focuses on practical evidence-based approaches to common presentations in primary care. The articles address key decisions that a clinician may encounter during initial assessment. The information presented can usually be covered in a typical primary care appointment. Articles should be no longer than 650 words, should include one box, figure or table and should begin with a very brief description ( 75 words or less) of the clinical situation. The decisions addressed should be presented in the form of questions. A box providing helpful resources for the patient or physician is encouraged.

CMAJ remains committed to notifying readers in a timely way about advisories and warnings pertaining to serious adverse drug events. A collection of recent drug advisories from Health Canada and the US Food and Drug Administration is regularly updated at www.cmaj.ca /misc/advisories.xhtml. 